\title{
Prioritizing the Factors Affecting Brand Equity of Popular Football Clubs in Iran
}

\author{
${ }^{1}$ Seyed Nasrollah Sajjadi ${ }^{*}{ }^{1}$ Rasoul Tarighi, ${ }^{1}$ Mohammad Abedlati \\ ${ }^{1}$ Department of Sport Management, Faculty of Sport Sciences, University of Tehran, Tehran, Iran.
}

\begin{abstract}
Background. Today, Building strong brands, Because of the extraordinary advantages that it creates, have been the marketing priorities of many organizations. Strong brands for a company, Creates an identity in the market. Objectives. This study aimed at Prioritizing factors affecting brand equity of popular football clubs in Iran. Methods. The design of the study was descriptive with practical goals. The participants of the study included two groups; the first group consisted of marketing and sport experts and sport managers. The participants in the second group were the fans of the mentioned clubs. There were 163 and 384 participants in the first and second group, respectively who were randomly selected through Morgan table. The instrument used to gather data was a likert questionnaire including 59 questions. This questionnaire was validity- checked by the study professors, and its reliability was measured 0.95 by cronbach alpha statistical test. Descriptive data analysis was done for population description and their responses. Partial least squares test was also performed for analytic analysis. SPSS 18 was the software for data analysis. Results. The results of the study showed that from the managers and experts' and fans perspective, the factors affecting the brand equity of Perspolis and Esteghlal football clubs In order of priority were the team's history, management, team's success, head coach, stadium, sponsors, team's stars, media, fans loyalty and logo. Conclusion. According to the results, It seems that managers of Popular clubs like Esteghlal and Persepolis, to promote their club brand equity should have the necessary attention to factors such as team's history, management, team's success, head coach, stadium, sponsors, team's stars, media, fans loyalty and logo.
\end{abstract}

KEY WORDS: Sport Industry, Fundraising, Costumers, Partial Least Squares Method.

\section{INTRODUCTION}

It is necessary to have marketing knowledge and skill in economic enterprises to be successful in competitive arenas. Sport institutes can be considered as an important and inseparable part of a country's economic body. In line with development of public, professional, and championship sport in local and international area, these gain economic goals as well (1). Also, studying the performance of some of international sport organizations such as international sport federations and also of some national organizations of different countries shows that they have used different techniques of sport marketing to achieve their goals and be significantly successful (2).

In fact, sport managers utilize marketing concepts and concepts pertinent to customers' requests. This belief originated from notions of

*. Corresponding Author: Seyed Nasrollah Sajjadi E-mail:nsajjadi@ut.ac.ir 
comprehensible quality. Meanwhile, one of the underlying concepts in many businesses is their brand, so that the management of the brand is located at the center of demand and prescription and the name of one brand takes a tangible role. Brands can introduce a product or sport services or a group of these products and services. Brand is something which influences customers and creates positive thinking by adding value to a product. Brand equity was firstly vastly used in 1980 and was known as an added value that a brand grants to one product (3). In 1989, Marketing Scientific Association defines brand equity: "An added value which is created for the product via the name in the market, margin of profit, or market share so that this added value can be considered as a financial capital and a set of desirable relationships and behaviors by customers and other members of the channel". Accordingly, brand equity is the consequence of consumers' perception of a brand, though this is affected by many factors (4).

By studying human brands in sports, Carlson and Donavan (2013) observed athletes as human brands having exclusive characteristics (5). When fans get familiar with athletes, they feel dependent on them and demand for shopping their belongings and also their team's belongings increases: fans then become more interested in watching games. In fact, the valuable capital of one team is not just their results, but also their brand place and brand equity. A club always attempts to promote its equity and reach the benefits of high brand value. First of all, branding attracts new customers and is useful in reminding customers about the company (5). In addition, Walsh and Lee (2012) in a dissertation entitled "Developing decision making model of branding development for the professional sport teams" have found that proposing and managing is a significant strategy for sport teams in regard with creating contact spot between spectators and the team and has this capability to have a positive impact on their beliefs (6). Blumrodt, Bryson, and Flanagan (2012) in their study have arrived to the conclusion that total brand management is considered a key issue in industry, and sport and professional football clubs are acting as a role model in this industry (7). Their brand is their main capital and their presence in competitions is accounted as a return of capital, which indicates management at a high level (7). Walsh and Lee (2012) have found that propounding and managing branding development is a significant strategy for sport teams for creating contact spot between spectators and the team, and that this has the capability to have a positive impact on their beliefs (6). Abosag, Roper, and Hind (2012) also investigated the relationship between an emotional state of branding and brand development among fans of sport clubs, showing that most of the time spectators reflect more commitment to their clubs as compared to the brands which are more well-known: the key point of this research is that fans of sport team do not like to look at their club as a brand in terms of commercial (8). Ross (2006) pinpointed that watching sport has been reduced during the last 20 years and this indicates that brands must be empowered to facilitate greater loyalty among customers (9). Owing to great importance of the issue, we must know what is happening in fans' mind. In another words, brand management is also dependent on fans' thoughts (9). In another study, Yee and Sidek (2008) in their research entitled "Effect of brand loyalty on the customers of sport clothes", which was done with 10 customers of sport clothes in Malaysia, reached the conclusion that there is a significant relationship between brand name, price, advertisement, quality of services and productions, production method, shops atmosphere, and loyalty to the brand of sport clothes (10).

With respect to the aforementioned cases, brand concept in our country varies considerably as compared to developed countries. This might be because marketers and mangers of the companies are not fully aware of the countless advantages of brand equity in our country, and still use traditional advertisement methods to communicate with fans and stabilize their brand: in fact, they do not have a correct perception of concepts such as brand, its management, and brand equity. Tehran Persepolis Football Club has the history of 51 years in Iran's football league and is accounted as one of the most experienced and popular football clubs in Iran. Moreover, this club has won nine championships in the Persian Gulf Pro League and has been selected as the fourth paramount club among all 
Asian football clubs in the twentieth century by International Federation of Football History and Statistics. Also, Esteghlal Tehran Football Club is one of the most popular football clubs in Iran. With two championships, two vice championships, and two third ranks in the AFC Champions League, it is accounted as Iran's most prestigious football club in Asian competitions and the third prestigious club in the history of Asia. Thus, it seems that paying attention to the matter of brand equity - which is part of the fundamental capitals of these two big clubs - can have considerable importance. In fact, brand equity of Esteghlal and Persepolis clubs is very low and it seems that many problems of these two popular Iranian football clubs can be resolved via escalating their brand equity. Despite the high value of the brands of football clubs in Asia and the world, Tehran Esteghlal and Persepolis football clubs are at the low rank of 170 and 178. A number of Asian clubs from South Korea, Japan, and the Persian Gulf countries are ranked under 100 in the trademark validation site (11) due to step-up importance of the value of the brand equity of football clubs all around the world, this dissertation attempts to detect factors affecting brand equity of the Tehran Esteghlal and Persepolis Football Cubs and specify prioritization of each of these factors.

\section{MATERIALS AND METHODS}

Participants. Statistical population of the research includes two groups of sport mangers and experts and fans of Tehran Esteghlal and Persepolis Football Clubs respectively. Statistical sample of the research encompasses 163 sport experts and managers who were purposefully selected and 384 fans of Esteghlal who were selected for available sampling form. Data collection method in the current study is filed method, done through quantitative data collection method.

Tools. Data collection tool for this study was researcher-made questionnaire in which variables derived from foreign researches were carried out in the context of brand equity: these included 10 main variables and 59 questions. Its validity was obtained by 15 expert professors of sport management and its reliability was determined equal to 0.95 via Cronbach's alpha test.

Statistical Analysis. In this study, descriptive statistic was applied to illustrate demographic status of the respondents. Also, because naturalness of the data was lower than 0.05 for all of the factors using Kolmogorov-Smirnov test, the assumption of the naturalness of the data was rejected for all of variables. There was no possibility to use parametric statistical tests, and so non-parametric statistical tests were applied. Therefore, paired least square test was used.

\section{RESULTS}

Owing to the descriptive results, 163 respondents to the research questionnaire - who are $29.7 \%$-were sport mangers and experts and 384 respondents-who are $70.3 \%$-were fans from both popular clubs. Descriptive results also revealed that 123 respondents-who are $22.5 \%$-were less than 25 years old. In addition, 184 respondents - who are 33.6\% - were between 25 and 35 . On the other hand, the lowest frequency of respondents was pertinent to the people over 45 years, including 45 persons equivalent to $8.2 \%$ of the respondents.

With respect to the issue that none of the research variables have normal distribution, partial least squares technique was employed to scrutinize the relationship between variables. In this regard, the correctness of the relationship between structures was verified and factors such as club history $(\mathrm{T}=3.67, \quad \beta=0.912)$, club management $(\mathrm{T}=3.69, \beta=0.881)$, team success $(\mathrm{T}=9.41, \quad \beta=0.820)$, head coach $\quad(\mathrm{T}=2.12$, $\beta=0.789)$, stadium $(T=7.06, \beta=0.770)$, Sponsors $(\mathrm{T}=8.99, \quad \beta=0.763)$, team stars $\quad(\mathrm{T}=4.32$, $\beta=0.741)$, media $(T=7.11, \beta=0.708)$, fans loyalty $(\mathrm{T}=5.02, \beta=0.649)$, and $\log \mathrm{o}(\mathrm{T}=6.30, \beta=0.590)$ were found to be affecting brand equity of Iran's popular football clubs (Fig 1).

\section{DISCUSSION}

The main purpose of this study was to Prioritizing factors affecting brand equity of popular football clubs in Iran. The values obtained from paired least square test show that club history, club management, team success, head coach, stadium, fans, team stars, media, 
fans loyalty, and logo are affecting brand equity of these popular Iranian football clubs.

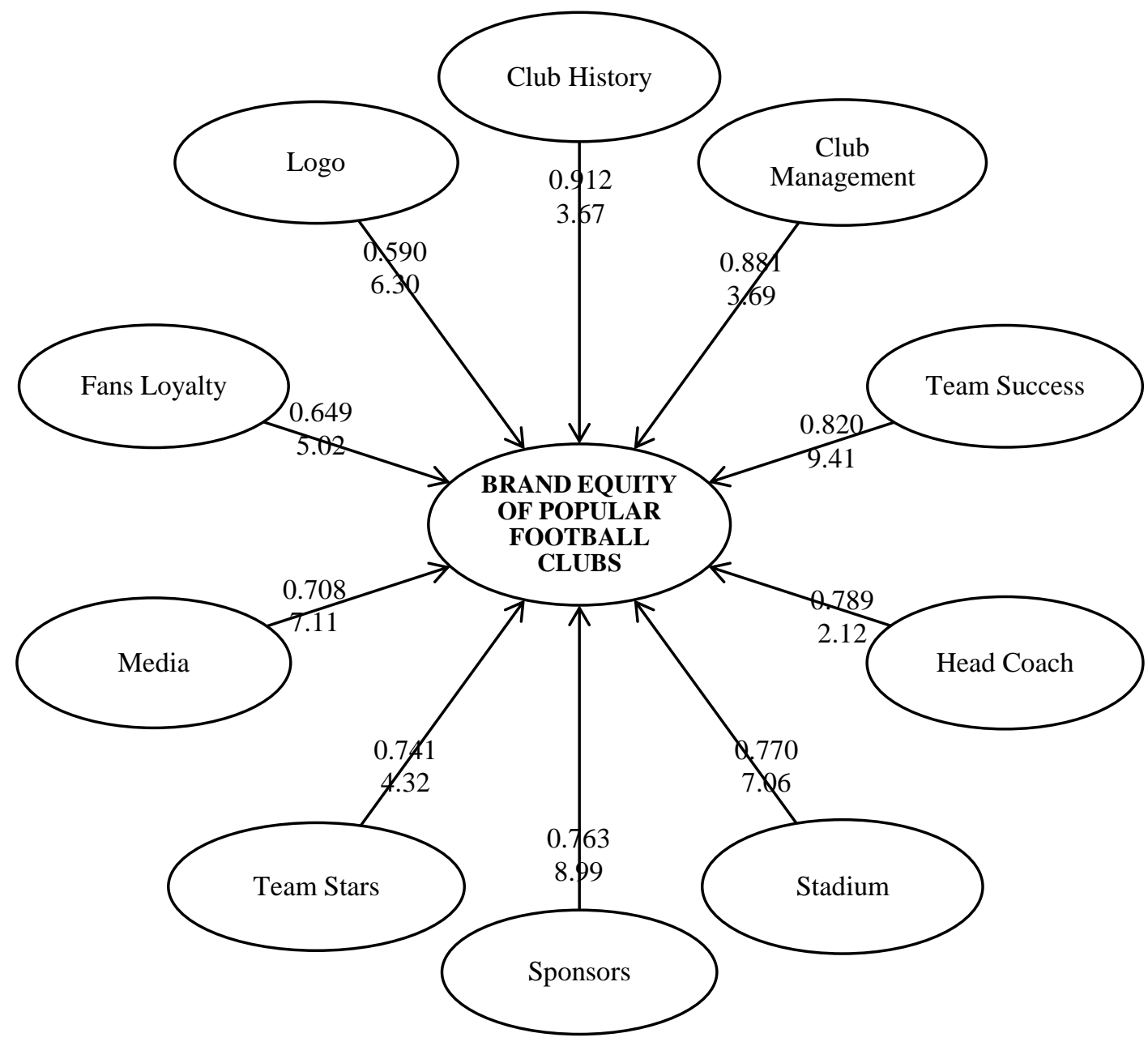

Figure 1. Structural model, values of T and factor weight of the main factors of research.

Given the results, the factors of club history, club management, and team success stood at the first to the third ranks of the factors affecting brand equity of these clubs. It seems that Esteghlal and Persepolis Clubs can give more credit to the history of their clubs by relying on their long and proud history internally, in Iran, as well as out in the world. Famous and popular players have also been part of these two popular teams of Tehran city. Also, they have to use expert and experienced managers in sport area in order to have better performance and reach their strategic goals. On the other hand, if these two clubs intend to have added value for the brand of their clubs, they must try to achieve significant success in local and international events. In this regard, some researchers have found out that the history of professional sport clubs is a significant factor determining brand equity of sport clubs, and that the history of professional clubs with reference to social recognition will enhance brand equity of the team. Also, factors such as honors, history, and popularity of the club are effective factors influencing brand equity of football clubs (12-14). In the case of the management factor, some researchers have arrived at the conclusion that good and strong managers with desirable capability and ability have a significant and positive effect on brand equity of professional football clubs $(12,15)$. Additionally, in line 
with the success factor of the team, it has been observed that team success is an effective factor for brand equity of basketball and football clubs $(12,16)$.

As results represent, factors of team's head coach, stadium, and sponsors stood at the fourth to sixth ranks of factors affecting brand equity of these football clubs. In fact, head coaches of popular teams like Esteghlal and Persepolis orchestrate greater success for their teams by proposing desirable ideas, proper exercise, and creating suitable relationship with managers and fans. It seems that owning a decent and high quality private stadium is necessary for both Esteghlal and Persepolis football clubs: this can have an essential effect on increasing the quality of team performance in exercises and competitions. Also, it seems that the relationship between clubs and sponsors can facilitate work, financial issues, and affairs associated with the club. In this regard, some studies have shown that the presence of a capable coach affects brand equity of sport clubs. Plus, research results show that head coach has effect on brand equity of football teams in the US Universal Football League $(12,17,18)$. In line with the stadium factor, dissertations have introduced the role of good, modern, and equipped stadia in brand equity of professional football and basketball clubs $(12,15,16)$. Also, in line with the factor of sponsors, they have found that sponsoring is one of the effective factors on brand equity of professional football clubs (19, 20).

As it was seen, factors of team stars, media, fans loyalty, and logo stood at the sixth to tenth ranks of factors affecting brand equity of these clubs. It seems that the presence of famous stars in professional football teams always has a significant role in bringing them domestic and international successes. Professional football clubs pick out their players purposefully because stars of one football team will lead to increased presence of fans in the stadium, and higher satisfaction among them. Also, it is necessary that these two clubs have a more appropriate relationship with different media to properly inform their fans of club's news because they are always followed by millions of fans. In addition, it seems that these two popular clubs of Tehran city have planned to commence activities such as selling cheaper tickets or holding lotteries and giving rewards at the time of matches in order to attract more fans, retain old ones, and create loyalty among fans,. On the other hand, it looks that a charming logo with appropriate content for both Tehran Esteghlal and Persepolis Football Clubs can be addressed as a competitive advantage. To do so, some inquiries have shown that the presence of known stars is effective for brand equity of sport teams. Also, a dissertation confirmed that the presence of stars leads to the development of brand equity of football teams in US Universal Football $(15,17,21)$. In keeping with the media factor, it is apparent that brand equity increases with use of the desirable media and with a robust relationship with customers and social media $(22,23)$. In line with the factor of fan loyalty, some dissertations found out that customers have an impact on increasing the value of brand equity of service organizations $(24,25)$. With reference to the logo factor, some papers have found out that good and attractive logos and brands have a significantly positive impact on brand equity of professional football and basketball clubs $(12,16)$

\section{CONCLUSION}

Given the research findings, Esteghlal and Persepolis Football Clubs need to have a specific plan to establish effective communication with their fans. They must be careful with hiring star players. Also, these clubs have to make endeavors to gain noteworthy successes in domestic and international events and arenas via formulated planning in various sections. They have to strive to have a standard stadium to enhance their quality of play. It is recommended that the managers of these clubs estimate the factors which have brought honor to their clubs in the past and consider these in their future planning. Furthermore, it is recommended that these two popular clubs be careful with selecting qualified and expert managers so that they move towards improvement optimally and efficiently. It is also recommended that these two clubs employ experienced and skilled coaches. Managers can 
propound desirable ideas, proper exercise, and create proper communication with fans. In this way they can lead their teams to greater success, and also have a better response to their countless fans. In addition to the aforementioned cases, and due to the results obtained from this study, it is suggested that these football clubs attempt to attract desirable sponsors because the relationship between clubs and sponsors can facilitate work, financial issues, and affairs pertinent to the club. Likewise, it is recommended that these two popular clubs pay attention towards designing an attractive and desirable logo for their clubs as a competitive advantage in order to facilitate communication with their fans.

Constraints of conducting this study included lack of concentration of fans of the two clubs to fill in questionnaire at the time of the contest. At the end, it is recommended that other researchers undertake further study in this context of detecting barriers affecting development of brand equity of the Tehran Esteghlal and Persepolis Clubs respectively and also undertake comparative studies on the brand equity of Iran's clubs with clubs from other countries.

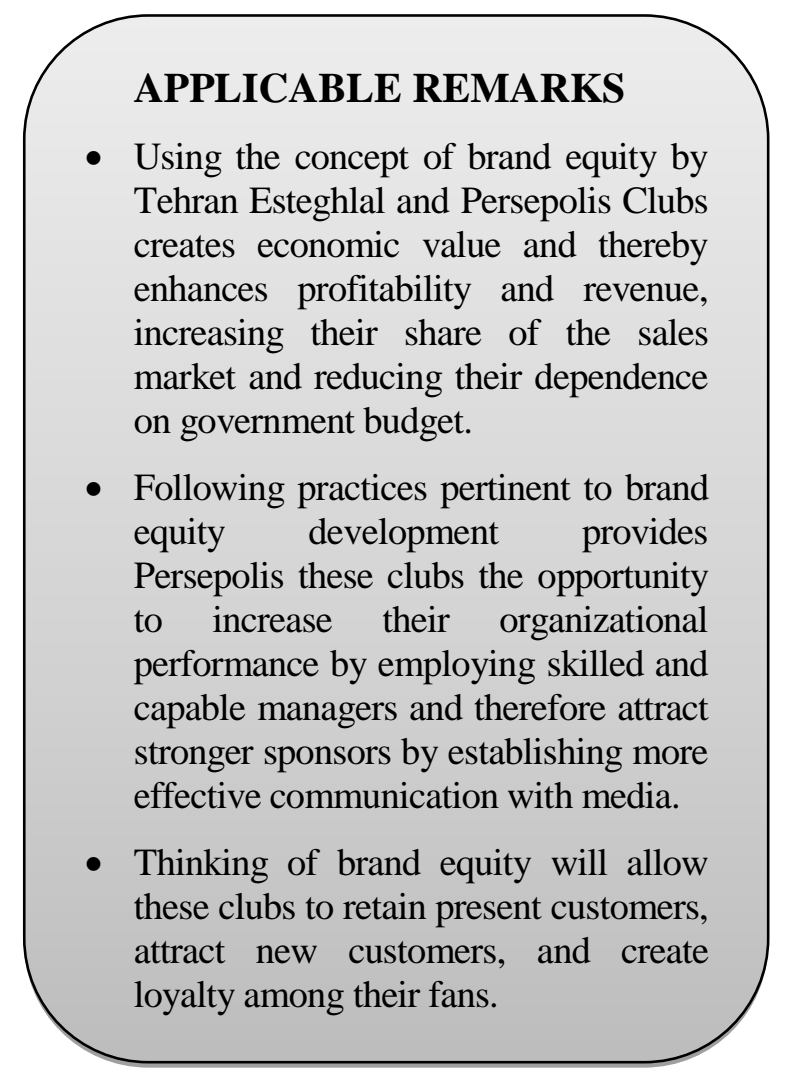

\section{REFERENCES}

1. Tarighi R, Hamidi M, Rajabi H. Designing Sport Marketing Model of National University Sport Federation of Ir. Iran. Journal of Research on University Sport. 2014;2(5):15-30 [Article in Farsi].

2. Tarighi R, Hamidi M, Rajabi H. Identifying Effective Factors in Development of Sport Marketing in University Sport of I.R. Iran. Sport Management Studies. 2017;8(40):113-30 [Article in Farsi].

3. Smit E, Bronner F, Tolboom M. Brand relationship quality and its value for personal contact. Journal of Business Research. 2007;60(6):627-33.

4. Norjaya Mohd Y, Mohd Nasser N, Osman M. Does image of country-of-origin matter to brand equity? Journal of Product \& Brand Management. 2007;16(1):38-48.

5. Carlson BD, Donavan DT. Human brands in sport: Athlete brand personality and identification. Journal of Sport Management. 2013;27(3):193-206.

6. Walsh P, Lee S. Development of a brand extension decision-making model for professional sport teams. Sport Marketing Quarterly. 2012;21(4):232-42.

7. Blumrodt J, Bryson D, Flanagan J. European football teams' CSR engagement impacts on customer-based brand equity. Journal of Consumer Marketing. 2012;29(7):482-93.

8. Abosag I, Roper S, Hind D. Examining the relationship between brand emotion and brand extension among supporters of professional football clubs. European Journal of Marketing. 2012;46(9):1233-51.

9. Ross SD. A conceptual framework for understanding spectator-based brand equity. Journal of Sport Management. 2006;20(1):22-38.

10. Yee AF, Sidek B. Influence of brand loyalty on consumer sportswear. International Journal of Economics and Management. 2008;2(2):221-36.

11. Brand Finance. Football 50 2017: The annual report on the most valuable football brands UK: The World's Leading Independent Branded Business Valuation and Strategy Consultancy; 2017 [Available from: http://brandfinance.com/images/upload/bf football_2017 report final june 6th_1.pdf.

12. Biscaia R, Correia A, Ross S, Rosado A, Maroco J. Spectator-based brand equity in professional soccer. Sport Marketing Quarterly. 2013;22(1):20-32. 
13. Boyle BA, Magnusson P. Social identity and brand equity formation: A comparative study of collegiate sports fans. Journal of Sport Management. 2007;21(4):497-520.

14. Watkins BA. Revisiting the social identity-brand equity model: An application to professional sports. Journal of Sport Management. 2014;28(4):471-80.

15. Gladden JM, Funk DC. Developing an understanding of brand associations in team sport: Empirical evidence from consumers of professional sport. Journal of Sport management. 2002;16(1):54-81.

16. Ross SD, Russell KC, Bang H. An empirical assessment of spectator-based brand equity. Journal of Sport Management. 2008;22(3):322-37.

17. Bruening JE, Lee M. The University of Notre Dame: an examination of the impact and evaluation of brand equity in NCAA Division I-A football. Sport Marketing Quarterly. 2007;16(1):38-48.

18. Funk DC, Pastore DL. Equating Attitudes to Allegiance: The Usefulness of Selected Attitudinal Information in Segmenting Loyalty to Professional Sports Teams. Sport Marketing Quarterly. 2000;9(4):175-84.

19. Henseler J, Wilson B, Westberg K. Managers' perceptions of the impact of sport sponsorship on brand equity: Which aspects of the sponsorship matter Most? Sport marketing quarterly. 2011;20(1):7-21.

20. Sajjadi SN, Rajabi H, Abed Lati M, Tarighi R. Identifying Factors Affecting Brand Equity of Professional Football Teams The Case Study of Esteghlal Tehran Football Club. Sport Management Studies. 2016;8(39):87102 [Article in Farsi].

21. Filo K, Funk DC, Alexandris K. Exploring the role of brand trust in the relationship between brand associations and brand loyalty in sport and fitness. International Journal of Sport Management and Marketing. 2008;3(12):39-57.

22. Sajjadi SN, Rajabi H, Abed Lati M, Tarighi R. A Study of the Factors Influencing Brand Equity of Tehran Persepolis Football Club. New Trends in Sport Management. 2014;1(3):43-52 [Article in Farsi].

23.Zailskaite-Jakste L, Kuvykaite R. Communication in social media for brand equity building. Economics and Management. 2013;18(1):142-53.

24. Alhaddad A. The effect of brand image and brand loyalty on brand equity. International Journal of Business and Management Invention. 2014;3(51):28-32.

25. Takali H, Hamidi M, Khabiri M, Sajjadi N, Alhani F. The Analysis of Experts' Perceived Experience of the Effective Factors in Brand Equity of Iranian National Olympic Committee. World Journal of Sport Sciences. 2012;6(4):441-51. 